\title{
Attribution of Global Monsoon Response to the Last Glacial Maximum Forcings
}

\author{
JIAN CAO \\ Earth System Modeling Center/Key Laboratory of Meteorological Disaster, Ministry of Education/Joint International \\ Research Laboratory of Climate and Environment Change/Collaborative Innovation Center on Forecast \\ and Evaluation of Meteorological Disasters, Nanjing University of Information Science \\ and Technology, Nanjing, China
}

\section{BIN WANG}

Earth System Modeling Center/Key Laboratory of Meteorological Disaster, Ministry of Education/Joint International Research Laboratory of Climate and Environment Change/Collaborative Innovation Center on Forecast and Evaluation of Meteorological Disasters, Nanjing University of Information Science and Technology, Nanjing, China, and Department of Atmospheric Sciences and International Pacific Research Center, University of Hawai'i at Mānoa, Honolulu, Hawaii

\section{LIBIN MA}

Earth System Modeling Center/Key Laboratory of Meteorological Disaster, Ministry of Education/Joint International Research Laboratory of Climate and Environment Change/Collaborative Innovation Center on Forecast and Evaluation of Meteorological Disasters, Nanjing University of Information Science and Technology, Nanjing, China

(Manuscript received 18 December 2018, in final form 11 June 2019)

\begin{abstract}
Investigation of global monsoon (GM) responses to external forcings is instrumental for understanding its formation mechanism and projected future changes. Coupled climate model experiments are performed to assess how the individual and full Last Glacial Maximum (LGM) forcings change GM precipitation. Under the full LGM forcing, the annual and local summer-mean GM precipitation are reduced by $8.5 \%$ and $10.8 \%$, respectively, compared to the results in the preindustrial control run; and the reduction of Northern Hemisphere (NH) summer monsoon (NHSM) precipitation is twice as large as its Southern Hemisphere (SH) counterpart (SHSM). The NH-SH asymmetric response is mainly caused by the monsoon circulation changeinduced moisture convergence rather than the reduction of moisture content, but the root cause is the continental ice sheet forcing. The NHSM precipitation changes dramatically differ among various single-forcing experiments, while this is not the case for their SH counterparts. The moisture budget analysis indicates the NHSM is dynamically oriented, but SHSM is thermodynamically oriented. The markedly different NHSM circulation changes are caused by different forcing-induced sea surface temperature (SST) patterns, including the North Atlantic cooling pattern forced by the continental ice sheet, the mega-La Niña-like pattern resulting from the greenhouse gas forcing, and the Indian Ocean dipole-like SST pattern caused by the land-sea configuration forcing. Moreover, the distinctive change of "monsoonality" in the Australian-Indonesian monsoon is predominantly forced by the exposure of the land shelf, which enhances precipitation during early summer (November-December) but weakens it in the rest of the year.
\end{abstract}

\section{Introduction}

The monsoon system is primarily driven by the annual variation of the solar radiation. The global monsoon (GM) has been viewed as a global-scale seasonal reversal of three-dimensional monsoon circulation and its

Corresponding author: Jian Cao, jianc@nuist.edu.cn associated migration of precipitation (Trenberth et al. 2000; Wang and Ding 2006, 2008). It is influenced by both the internal variability of the Earth system, such as El Niño-Southern Oscillation, the Atlantic multidecadal oscillation, and the interdecadal Pacific oscillation, and external forcings, such as the Earth orbital forcing, land-sea configuration, continental ice sheet, and greenhouse gas concentrations, at various time 
scales (Zhou et al. 2008; Liu et al. 2009; Cheng et al. 2012; Hsu et al. 2012; Mohtadi et al. 2016; B. Wang et al. 2014; Wang et al. 2017; Wang et al. 2018).

The GM is influenced by external forcings over centennial or longer time scales (Weber and Tuenter 2011; Mohtadi et al. 2016; Wang et al. 2017). The Last Glacial Maximum (LGM) is an ideal paleoclimate period to study GM response to external forcings, because during LGM multiple external forcings, including orbital effects, continental ice sheet, land-sea configuration, and greenhouse gases (GHG), differ from the preindustrial (PI) period. Therefore, an improved understanding of the GM responses to different external forcings of the LGM is instrumental for deepening our understanding of GM's future changes under increased anthropogenic forcings.

It has been recognized that the various forcings mentioned above have differing impacts on GM precipitation, a key parameter in the global hydrological cycle. Seasonal change of insolation induced by the orbital parameters' change can significantly modulate the "monsoonality" during the mid-Holocene (Kutzbach 1981; Kutzbach and Otto-Bliesner 1982; Liu et al. 2004). The intensity of solar radiation is closely linked with the global-mean monsoon precipitation. Liu et al. (2009) have shown, with numerical experiments, that over the past 1000 years the simulated GM precipitation was weak during the Little Ice Age (1450-1850) with the three weakest periods occurring around 1460, 1685, and 1800, corresponding to, respectively, the Sporer Minimum, Maunder Minimum, and Dalton Minimum periods of solar activity. Conversely, a strong GM was simulated during the model Medieval Warm Period (ca. 10301240). The waxing and waning of continental ice sheet, a predominant glacial-interglacial feature of Earth's climate change, can influence monsoon activity by altering surface albedo and topography (Yin et al. 2009; Bhattacharya et al. 2017). The freshwater intrusion due to melting of ice sheets could weaken the Atlantic meridional overturning circulation and cool North Atlantic SST, leading to weak regional monsoons (Chiang and Bitz 2005; Marzin et al. 2013). Besides the ice sheet forcing, orbital forcing and GHG forcing could modulate the monsoon periodicity. The buildup of continental ice sheet causes sea level drop and exposes the continental shelf, especially over the Maritime Continent region, and considerably reduces the Indo-Pacific warm pool precipitation by the associated weakening of the Walker circulation (De Deckker et al. 2003; DiNezio et al. 2011, 2016, 2018; Cao et al. 2019).

The main features of the LGM climate were documented by abundant proxy data. Pollen-based continental precipitation reconstruction and multisource paleo-records both indicate a reduction of precipitation over most parts of the globe (Bartlein et al. 2011; DiNezio and Tierney 2013). Reconstructed precipitation over the Asian-Australian region is considerably reduced due to the weakened Pacific Walker circulation during the LGM compared to today's precipitation (DiNezio and Tierney 2013; DiNezio et al. 2018). Monsoon precipitation derived from highresolution oxygen isotopic records reveals that precipitation change has an antiphase relationship between hemispheres (Wang et al. 2006). An antiphase relationship exists between the Asian and South American monsoon systems on a wide range of time scales (Cheng et al. 2012; Mohtadi et al. 2016). This relationship could be explained by the swing of the intertropical convergence zone (ITCZ), whose variation is closely linked to the GM activities (Braconnot et al. 2007; Wang et al. 2017). Furthermore, model-data comparison studies reveal that regional monsoon precipitation changes coherently over the Northern or Southern Hemispheres during the LGM, although the Australian-Indonesian (AI) monsoon region shows different monsoonality (Braconnot et al. 2000; Lewis et al. 2010; Chevalier et al. 2017; Jiang and Lang 2010; Cook and Vizy 2006; Mohtadi et al. 2011).

Numerical simulations support the monsoon precipitation features inferred from the proxy data. Full forcing experiments showed a weakening of the mean GM precipitation through the cooling and drying of the atmosphere (Jiang et al. 2015; Yan et al. 2016). The change of AI monsoonality was linked to the adjacent atmosphere-ocean circulation change associated with the prominent change in the Walker circulation (Mohtadi et al. 2017; DiNezio et al. 2016, 2018; Yan et al. 2018). However, it remains unclear how the individual LGM forcing affects the GM changes and how the multiforcing works together to determine the coherent GM changes. To this end, individual forcing experiments are required.

An important aspect of the LGM climate is the hemispheric asymmetry between the Northern Hemisphere $(\mathrm{NH})$ and Southern Hemisphere $(\mathrm{SH})$ as indicated by both proxy data and model simulation. Insights into the physical mechanisms responsible for the hemispheric asymmetry of monsoon precipitation change are essential for understanding the past, present, and future monsoon changes. Liu et al. (2004) found that the enhancement (reduction) of $\mathrm{NH}(\mathrm{SH})$ insolation seasonal cycle leads to strengthened (weakened) $\mathrm{NH}$ (SH) monsoon precipitation. Liu et al. (2009) found that the $\mathrm{NH}$ monsoon precipitation is more sensitive to the GHG forcing while its SH counterpart is more sensitive 
to solar and volcanic radiation forcing during the last millennium, suggesting that the hemispheric monsoon precipitation change is forcing-dependent. Additionally, the projected future GM precipitation change is dominated by the GHG forcing, which enhances the $\mathrm{NH}$ monsoon precipitation but weakens the $\mathrm{SH}$ one (Lee and Wang 2014). Those studies all support that different forcings may induce hemispherically asymmetric responses of monsoon precipitation.

To reveal the effects of the individual LGM forcings on the GM precipitation and to better understand the hemispheric-scale monsoon precipitation responses to different forcings, we specifically designed a suite of single/combined-forcing sensitivity experiments in addition to the PI and full-forcing LGM experiments. The experimental design and model validation are introduced in section 2. Section 3 evaluates global and hemispheric monsoon changes under different forcings. The moisture diagnosis and analysis are presented in section 4 . The possible physical mechanisms responsible for monsoon precipitation changes are discussed in section 5. Concluding remarks are given in section 6 .

\section{Experimental design and model validation}

\section{a. Model and experiments}

The Nanjing University of Information Science and Technology Earth System Model version 1 (NESM v1; Cao et al. 2015), is used to investigate the influence of LGM forcings on GM precipitation change. The atmospheric, ocean, and sea ice component models are the European Centre Hamburg Model (ECHAM v5.3; Roeckner et al. 2003), Nucleus for European Modelling of the Ocean v3.4 (NEMO v3.4; Madec et al. 2012), and Los Alamos sea ice model (CICE v4.1; Hunke and Lipscomb 2010), respectively. The atmospheric model resolution is $\mathrm{T} 42 \mathrm{~L} 31$, which corresponds to a horizontal resolution of $2.8^{\circ}$ in the zonal and meridional directions and 31 vertical layers. The horizontal resolution of the land surface model is the same as for the atmospheric model. The ocean model configuration is ORCA2, which corresponds to $2^{\circ}$ in the zonal and meridional directions and is refined in meridional direction over tropics, and the resolution of sea ice model is $1^{\circ}$ latitude $\times 0.5^{\circ}$ longitude. The NESM v1 is evaluated under the modern climate forcing, and its finerresolution version shows better performance in simulating the global monsoon precipitation (Cao et al. 2015). The NESM v1 is also employed in understanding the mechanism of GM decadal change (Wang et al. 2018) and used to study the LGM climate change (Cao et al. 2019). It has been developed to include a more comprehensive ESM, NESM v3, in order to participate in the CMIP6 project (Cao et al. 2018).

To distinguish GM response to different external forcings during the LGM, four external LGM forcings are considered: lowered GHG concentrations, expanded continental ice sheets, changing of land-sea configuration, and Earth's orbital parameters. The forcings are the same as those employed in the PMIP3 protocol, and the detailed documentation for the forcing and boundary condition can be found at https:// pmip3.lsce.ipsl.fr. Here, seven experiments are designed: the preindustrial control simulation (PI), the LGM full-forcing experiment (LGM), the greenhouse gas (GHG), ice sheet (IS), land-sea configuration (LSC), and Earth orbital (EO) single-forcing sensitivity experiments, and the combined IS and LSC forcing experiment (IS-LSC). The design of the PI and LGM experiments is the same as specified in the PMIP3 protocol. In the LGM experiment, the aforementioned four forcings are simultaneously considered, and all forcings are taken equal to their LGM values. The single-forcing sensitivity experiments are based on the PI control experiment with the perturbation of a single forcing. In the GHG experiment, the concentrations of $\mathrm{CO}_{2}, \mathrm{CH}_{4}$, and $\mathrm{NO}_{2}$ are lowered to $185 \mathrm{ppm}, 350 \mathrm{ppb}$, and $200 \mathrm{ppb}$, respectively. The LGM ice sheets forcing is a blended product obtained by averaging three different ice sheet reconstructions: ICE-6G v2.0 (Argus and Peltier 2010), Meltwater Routing and OceanCryosphere-Atmosphere response (MOCA; Tarasov and Peltier 2004), and that of the Australian National University (Lambeck et al. 2010). This ice sheets forcing is specified in the IS experiment. The LSC experiment is the same as the PI experiment except for imposing the LGM land-sea configuration and topography. Earth's orbital parameters are set to the LGM values in the EO experiment. In addition, the combined effect of continental ice sheets and land-sea configuration change is considered in the IS-LSC experiment. Besides the abovementioned four type of external forcings, the runoff, land surface vegetation, and aerosol are specified as the PI condition. The additional continental shelves due to the lower sea level are set to the same vegetation types from neighboring grid cells in zonal direction. The omission of vegetation change in the experimental design may underestimate the monsoon precipitation reduction because a dynamic vegetation may amplify the precipitation reduction through negative feedback (Schneider von Deimling et al. 2006). Detailed experimental designs and lengths of experiment integrations of all simulations are introduced in Cao et al. (2019) and summarized in Table 1 . The model stability, shown by the surface temperature evolutions, is assessed by 
TABLE 1. The experimental design of the PI control experiment, LGM experiment, and five sensitivity experiments.

\begin{tabular}{|c|c|c|c|c|c|c|c|}
\hline & PI & LGM & GHG & IS & LSC & IS-LSC & $\mathrm{EO}$ \\
\hline Eccentricity & 0.016724 & 0.018994 & \multirow[t]{3}{*}{ PI } & \multirow[t]{3}{*}{ PI } & \multirow[t]{3}{*}{ PI } & \multirow[t]{3}{*}{ PI } & \multirow[t]{3}{*}{ LGM } \\
\hline Obliquity $\left(^{\circ}\right)$ & 23.446 & 22.949 & & & & & \\
\hline Perihelion $\left({ }^{\circ}\right)$ & 282.04 & 294.42 & & & & & \\
\hline $\mathrm{CO}_{2}(\mathrm{ppm})$ & 280 & 185 & \multirow[t]{3}{*}{ LGM } & \multirow[t]{3}{*}{ PI } & \multirow[t]{3}{*}{ PI } & \multirow[t]{3}{*}{ PI } & \multirow[t]{3}{*}{ PI } \\
\hline $\mathrm{CH}_{4}(\mathrm{ppb})$ & 650 & 350 & & & & & \\
\hline $\mathrm{N}_{2} \mathrm{O}(\mathrm{ppb})$ & 270 & 200 & & & & & \\
\hline Ice sheets & PI & LGM & PI & LGM & PI & LGM & PI \\
\hline Land-sea configuration & PI & LGM & PI & PI & LGM & LGM & PI \\
\hline Vegetation & \multicolumn{6}{|c|}{ As in PI for all experiments } & \\
\hline Aerosol & \multicolumn{7}{|c|}{ As in PI for all experiments } \\
\hline Integration length (yr) & 1200 & 2000 & 1200 & 1400 & 1200 & 1500 & 1200 \\
\hline
\end{tabular}

Cao et al. (2019). Here, the quasi-equilibrium state requires the global-mean surface air temperature (TAS) trend to be less than $0.02 \mathrm{~K}_{\text {century }}{ }^{-1}$. The last 100 years of data from each simulation are used to examine the GM changes.

\section{b. Model validation}

The performance of NESM v1 in simulating the PI and LGM climatology and the model's response to the full LGM forcing have been assessed by Cao et al. (2019). The simulated annual-mean TAS and precipitation in the PI experiment agree very well with the multimodel ensemble mean from phase 5 of the Coupled Model Intercomparison Project (CMIP5) (figure not shown). The pattern correlation coefficient for precipitation and TAS are 0.94 and 0.99 , respectively. The responses of TAS and precipitation in the NESM v1 are similar to the results of the PMIP3 models (Kageyama et al. 2013; Zheng and Yu 2013; Brady et al. 2013).

The simulated GM precipitation and domain in the PI experiment are compared with observations in Fig. 1. The GM precipitation intensity is defined by the ratio of precipitation annual range to the annual total. Here annual range is defined as the precipitation difference between local summer and winter, which means MaySeptember (MJJAS) precipitation minus NovemberMarch (NDJFM) precipitation in the NH and NDJFM minus MJJAS mean precipitation in the SH. The GM precipitation domain refers to the regions where the precipitation annual range exceeds $2.5 \mathrm{~mm} \mathrm{day}^{-1}$ and the GM precipitation intensity exceeds 0.55 (Wang et al. 2012). The observed precipitation data are the arithmetic mean of Global Precipitation Climatology Project (GPCP), version 2.2 (Huffman et al. 2009), and Climate Prediction Center Merged Analysis of Precipitation (CMAP) data (Xie and Arkin 1997) in the period of 1979-2008. The model well captures the major monsoon rainy regions over northern and southern Africa, Asia, North and South America, and Australia (Fig. 1b).
However, the simulated oceanic monsoon is stronger than the observations. Without specific mention, the monsoon region used in this paper refers to the fixed present-day monsoon domain (Fig. 1a).

\section{Monsoon precipitation changes}

Both paleo-proxy records and model simulations reported weakened GM precipitation and precipitation annual range during the LGM (Bartlein et al. 2011; Cheng et al. 2012; Jiang et al. 2015). These changes could be better reflected by examining the annual cycle of precipitation in the $\mathrm{NH}$ and $\mathrm{SH}$ monsoon domains instead of the entire GM domain, since the monsoonality is different in the $\mathrm{NH}$ and $\mathrm{SH}$ and the hemispheric monsoon precipitation changes are forcing-dependent (Liu et al. 2004; Liu et al. 2009; Lee and Wang 2014).
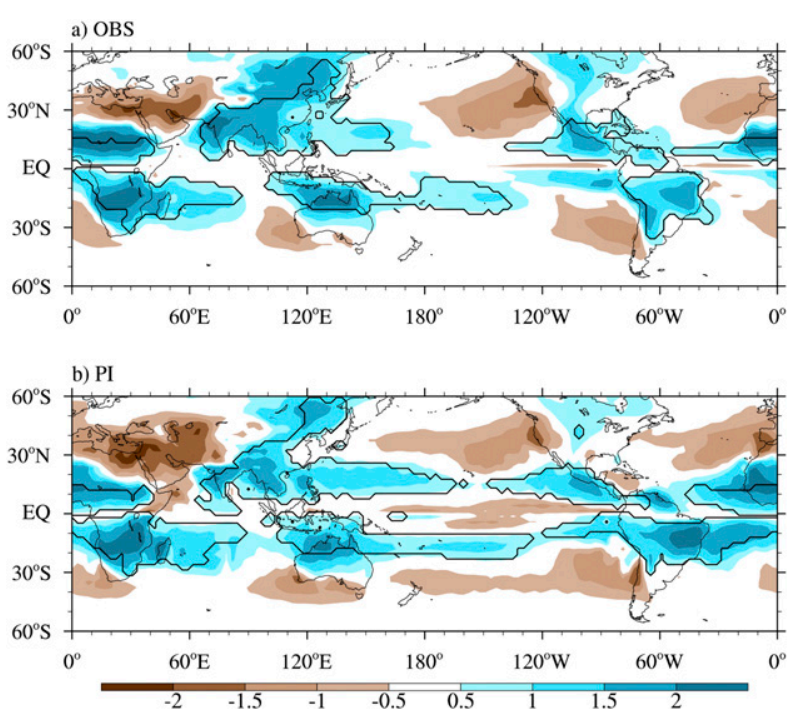

FIG. 1. The global monsoon intensity (shaded) and domain (contours) in (a) GPCP observational data and (b) the PI control experiment. 

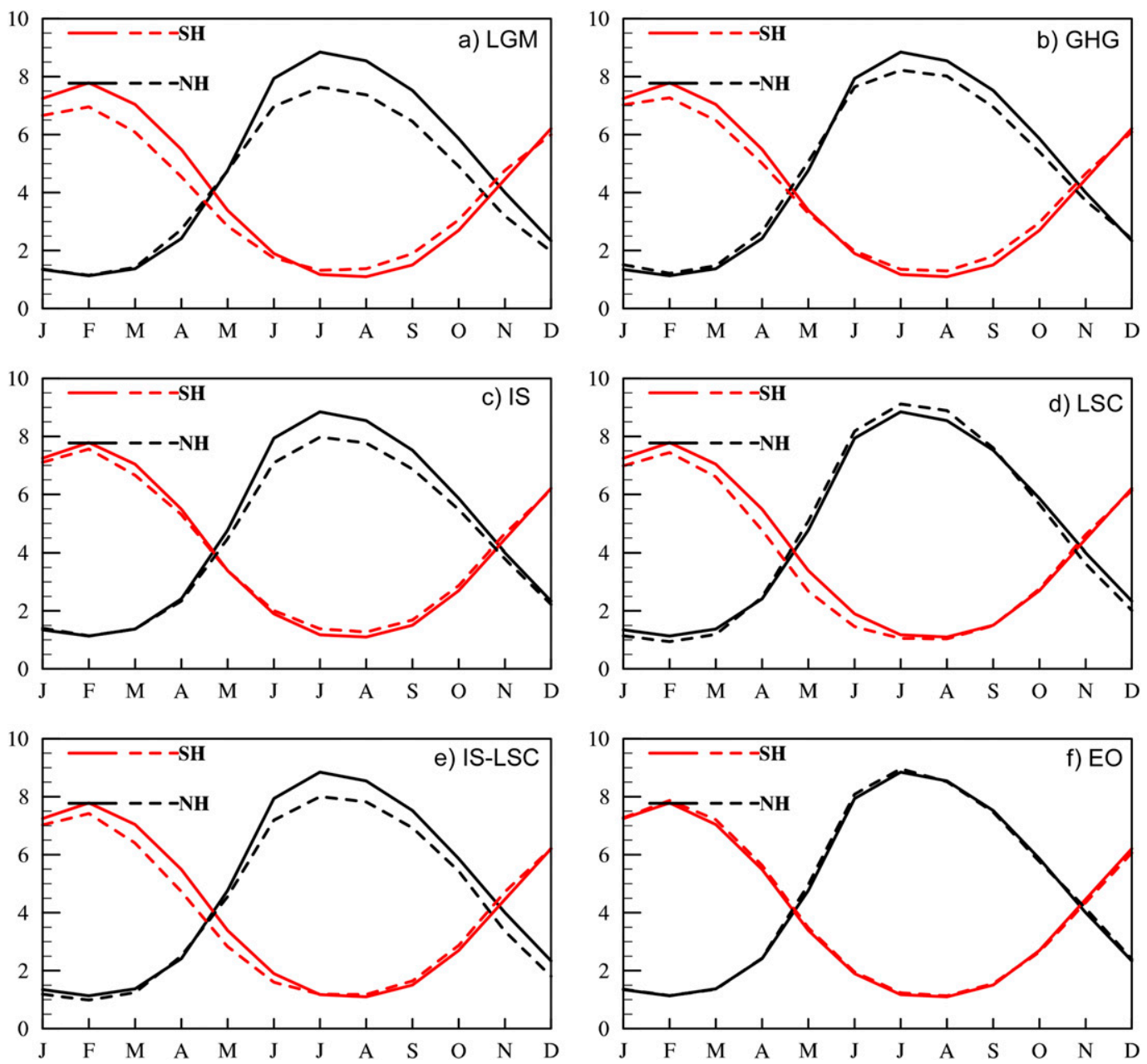

FIG. 2. Comparison of hemispheric-average monsoon precipitation $\left(\mathrm{mm} \mathrm{day}^{-1}\right)$ simulated by sensitivity experiments and the PI control experiment (solid lines). The dashed lines represent the results from the (a) LGM, (b) GHG, (c) IS, (d) LSC, (e) IS-LSC, and (f) EO experiments. The monsoon precipitation is averaged over the observed monsoon domain.

Figure 2 shows the comparison between the hemispherically averaged monsoon precipitation in the LGM and the sensitivity experiments in comparison with those in the PI experiment over the observed monsoon domain. In the LGM experiment (Fig. 2a), a significant decrease of precipitation is evident from May to September over the $\mathrm{NH}$ compared to PI. Over the SH, the precipitation response is decreased in the austral summer and autumn and increased in the winter and spring seasons compared to PI. This is consistent with the monsoonality change in PMIP3 multimodel ensemble results (Yan et al. 2016). Precipitation changes induced by the reduced GHG and ice sheet forcings are both characterized by a dry local summer in both hemispheres (Figs. 2b,c). In contrast, the change of land-sea configuration produces a wet summer and a dry winter over the $\mathrm{NH}$ and a stronger drying in the austral summer and autumn over the SH (Fig. 2d). When the IS and LSC forcings are simultaneously imposed, the $\mathrm{NH}$ monsoon precipitation change resembles the IS experiment result (Fig. 2e), while the SH monsoon response is similar to the result of the LSC experiment (Fig. 2c). The change of Earth's orbital parameters alters the seasonal cycle of solar irradiance, but the monsoon precipitation change is insignificant (Fig. 2f) since the response of surface temperature change to the solar radiation change is small (figure not shown).

Overall, the change of monsoon precipitation seasonality is more significant in the local summer season under different forcings. It not only reflects the annual range change, but also represents the annual-mean precipitation change, simply because the summer monsoon rainfall dominates the annual-mean rainfall. The decrease in LGM Northern Hemisphere summer 

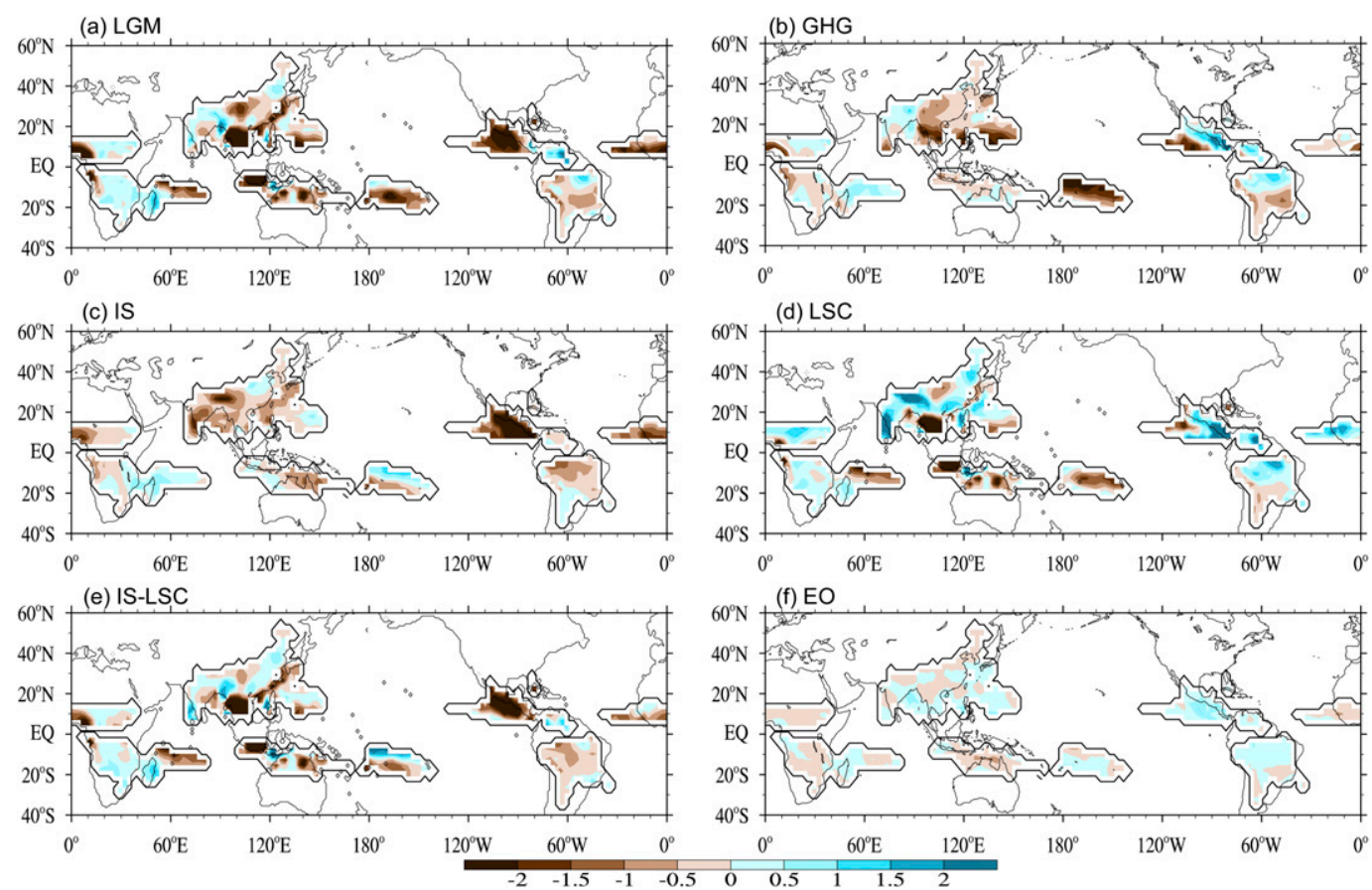

FIG. 3. Local summer monsoon precipitation $\left(\mathrm{mm} \mathrm{day}^{-1}\right)$ relative to the PI control experiment over the observed global monsoon domain in (a) LGM, (b) GHG, (c) IS, (d) LSC, (e) IS-LSC, and (f) EO.

monsoon (NHSM) precipitation is dominated by the weakened precipitation due to the lower GHG and presence of ice sheets. Meanwhile, the GHG, IS, and LSC forcings all contribute to the decreased Southern Hemisphere summer monsoon (SHSM) precipitation. In addition, the EO forcing is negligible in changing monsoon precipitation.

Monsoon precipitation may show coherent variability over the hemispheric or global scale due to the Earth system's internal variability or external forcings, which was previously found in instrumental observation, paleo-proxy data, and paleoclimate modeling (Wang et al. 2006; Liu et al. 2009; P. X. Wang et al. 2014; Wang et al. 2017). Figure 3 shows the spatial patterns of local summer monsoon precipitation changes relative to the PI experiment in the LGM full forcing and sensitivity experiments over the observed monsoon domain. Overall, dry signals are shown globally in the GHG and IS experiments except over the North American land monsoon region in the GHG experiment. The NHSM changes are larger than the SHSM in general, indicating a hemispherically asymmetric response of monsoon precipitation (Table 2). Indeed, the mean NHSM precipitation is reduced by $0.89 \mathrm{~mm} \mathrm{day}^{-1}$ in the LGM experiment, which is nearly twice as much as that in the $\mathrm{SH}\left(0.47 \mathrm{~mm} \mathrm{day}^{-1}\right)$. The hemispherically asymmetric response is also valid in the PMIP3 model. Over the observed GM domain, the multimodel ensemble mean of NHSM precipitation is reduced by $0.72 \mathrm{~mm}$ day $^{-1}$ which is 2.6 times as much as that in the SHSM. This indicates that the hemispherically asymmetric SM responses are robust during the LGM period. This is consistent with the results from proxy data studies (Wang et al. 2006; Cheng et al. 2012). The NHSM precipitation is reduced by $0.35,0.63$, and $0.69 \mathrm{~mm}^{-1 a y}{ }^{-1}$ in the GHG, IS-LSC, and IS sensitivity experiments, respectively (Table 2). Correspondingly, the SHSM precipitation is only reduced by $0.26,0.21$, and $0.14 \mathrm{~mm}^{-1 a y}{ }^{-1}$ (Table 2). Both the IS-LSC and IS experiments have large hemispherically asymmetric precipitation responses, suggesting that the hemispherically asymmetric summer monsoon precipitation response during the LGM is mainly due to the presence of continental ice sheets, whereas the GHG contribution is smaller (Fig. 3, Table 2).

TABLE 2. Global and hemispheric-average local summer monsoon precipitation change $\left(\mathrm{mm} \mathrm{day}^{-1}\right)$ relative to the PI control experiment in LGM and sensitivity experiments. The monsoon precipitation is obtained over the observed monsoon domain, as indicated in Fig. 1a.

\begin{tabular}{lcccccc}
\hline & LGM & GHG & IS & LSC & IS-LSC & EO \\
\hline Global & -0.69 & -0.31 & -0.43 & 0.03 & -0.43 & 0.03 \\
NH & -0.89 & -0.35 & -0.63 & 0.24 & -0.69 & 0.07 \\
SH & -0.47 & -0.26 & -0.14 & -0.21 & -0.21 & -0.01 \\
\hline
\end{tabular}



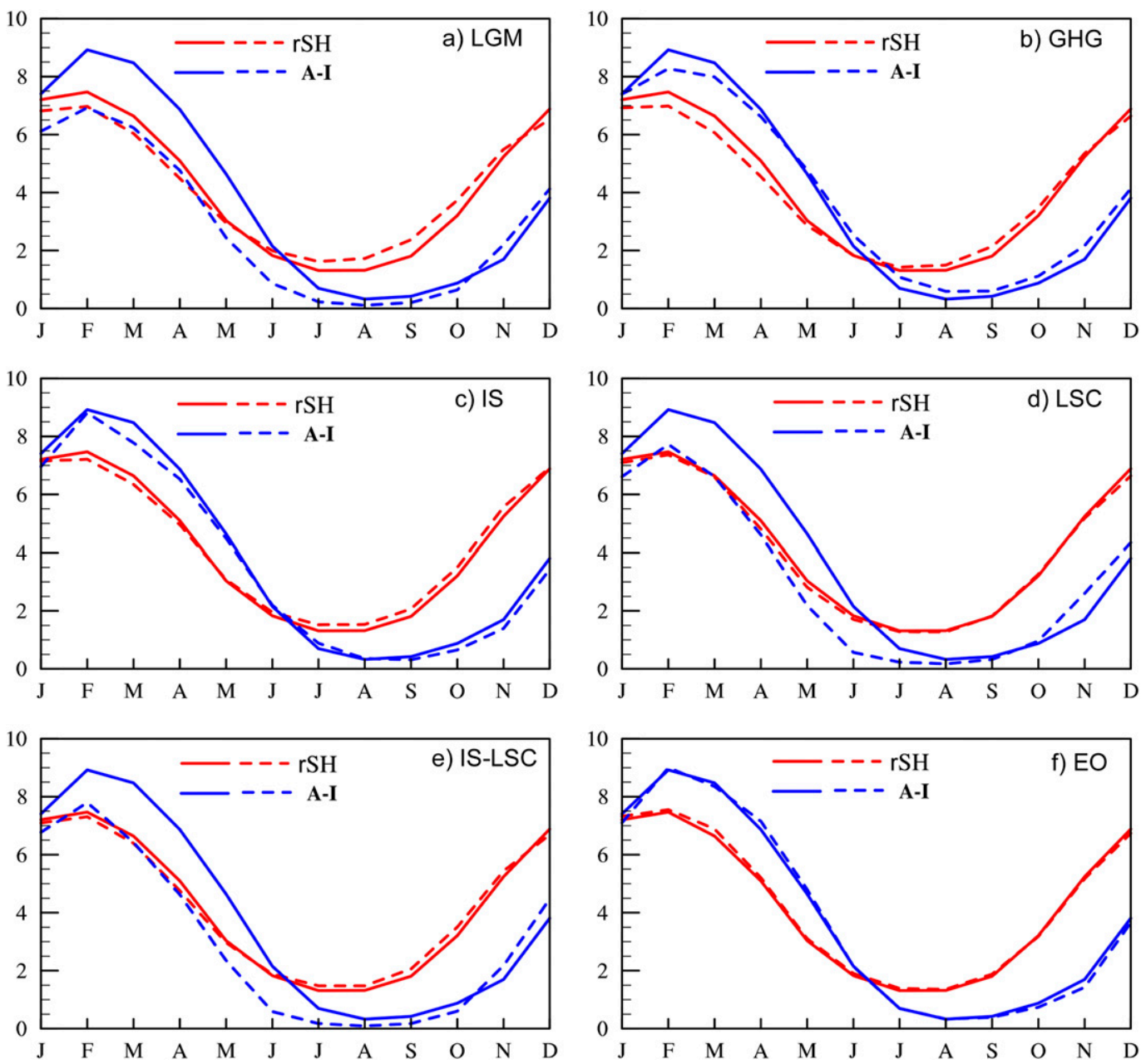

FIG. 4. Comparison of the $\mathrm{SH}$ monsoon precipitation $\left(\mathrm{mm} \mathrm{day}^{-1}\right)$ simulated by sensitivity experiments and the PI control experiment (solid lines). The AI monsoon precipitation and the rest of the $\mathrm{SH}(\mathrm{rSH})$ monsoon precipitation are indicated by blue and red lines, respectively. The dashed lines represent the results from the (a) LGM, (b) GHG, (c) ISLSC, (d) LSC, (e) IS-LSC, and (f) EO experiments.

Of note is that in the LSC experiment, the NHSM precipitation is increased compared to the PI experiment (Fig. 3d), although the LSC forcing cools the surface temperature, which should reduce precipitation (Cao et al. 2019). In the EO experiment, all submonsoon changes are insensitive to the minor radiation change (Table 2). This is consistent with the small hemisphericaverage monsoon precipitation change (Fig. 2f). Given this, we will not discuss its effect on the precipitation change.

Results of the single-forcing experiments suggest that the GHG, IS, and LSC forcings all cool the surface temperature, with the GHG forcing being the dominant one (Cao et al. 2019). However, the NHSM precipitation reduction in the GHG experiment is only $50 \%$ of that in the IS experiment, whereas the LSC forcing increases NHSM precipitation (Table 2). The striking differences among the three experiments suggest that the temperatureprecipitation relationship (Liu et al. 2013) does not always hold over the $\mathrm{NH}$, although it still holds over the SH. Therefore, it is worthwhile to explore why the NHSM precipitation is more variable than that of the SHSM under different external forcings.

Furthermore, the AI region is a unique region where the monsoonality change is different from that of other submonsoons during the LGM (Yan et al. 2016, 2018). The PMIP3 MME simulates a wetter condition in the early austral summer and a drier condition in the rest of year, which enlarge the monsoon annual range. Therefore, it is of interest to separately investigate the monsoonality over this region. Figure 4 compares the monsoonality over $\mathrm{AI}$ and the rest of the SH monsoon domain. During the LGM, the AI monsoon precipitation is decreased from January to October, whereas it is increased in November 
and December (Fig. 4a). This is consistent with the PMIP3 MME results (Yan et al. 2016, 2018). The austral latesummer and autumn precipitation reduction is much larger over the AI region than over other $\mathrm{SH}$ monsoon regions, suggesting that the AI monsoon is the most sensitive regional monsoon to the full LGM forcing (Figs. 4a,d,e). When the lower GHG concentration, continental ice sheets, or Earth orbital forcing are imposed, the response of AI monsoon is similar to that of other $\mathrm{SH}$ monsoons, implying that those forcings may not be the major reason of the unique AI monsoon precipitation change (Figs. 4b,c,f). Over AI the austral early austral summer precipitation is increased and the late-summer and autumn monsoon precipitation is substantially reduced in the LSC experiment only, while the other SH monsoon regions are less affected, suggesting that the change of land-sea configuration is a more effective forcing in changing the AI monsoon rainfall. This feature is also shown in the IS-LSC experiment result, which indicates the critical role of the LSC forcing. It may be due to the local effect of land sea configuration change, which happens close to the $\mathrm{AI}$ region. At the meantime, the $\mathrm{AI}$ monsoon rainfall change in the LSC experiment is comparable with that of the LGM full forcing experiment (Figs. 4a,d,e).

What is the root cause of the hemispherically asymmetric response of monsoon precipitation? Why are the NHSM precipitation changes so different under the GHG, IS, and LSC forcings? What are the key processes for the AI monsoonality change under the LSC forcing? A moisture budget analysis may provide clues to address these questions.

\section{Moisture budget analysis results}

The column-integrated moisture tendency equation can be expressed as follows:

$$
\frac{\partial w}{\partial t}+\langle\nabla \cdot(q \mathbf{V})\rangle=E-P
$$

where $w$ is the total column-integrated water vapor, $\partial / \partial t$ is the time tendency, angle brackets indicate the vertical integration from the surface to $100 \mathrm{hPa}, \nabla$ is the gradient operator, $q$ is the specific humidity, $\mathbf{V}$ is the horizontal wind vector, and $E$ and $P$ are the surface evaporation and precipitation. Since all simulations are in a quasi-equilibrium state, the term $\partial w / \partial t$ would vanish. The change of monsoon precipitation could be further derived as

$$
P^{\prime}=-\langle\mathbf{V} \cdot \nabla q\rangle^{\prime}-\langle q \nabla \cdot \mathbf{V}\rangle^{\prime}+E^{\prime},
$$

where the prime means the difference between two experiments (e.g., LGM and PI experiments). The first term in the right-hand side is the change of moisture advection, and the second and third terms indicate the contribution of moisture convergence and surface evaporation, respectively. Here the monthly data were used to compute the moisture budget since the contribution of high-frequency eddies is relatively small as suggested by previous studies (e.g., Endo and Kitoh 2014).

The changes in both atmospheric circulation and moisture affect the moisture convergence and evaporation. Therefore, it is necessary to reveal their relative contributions. The changes of moisture convergence and evaporation could be further decomposed to the circulation change-related dynamic process, temperature change-related thermodynamic process, and their interactions. They are derived as follows:

$$
\begin{aligned}
-\langle q \nabla \cdot \mathbf{V}\rangle^{\prime}= & -\left\langle\bar{q} D^{\prime}\right\rangle-\left\langle q^{\prime} \bar{D}\right\rangle-\left\langle q^{\prime} D^{\prime}\right\rangle \\
E^{\prime}= & {\left[\rho C_{p}|\mathbf{V}|\left(q_{s}-q_{a}\right)\right]^{\prime} } \\
= & \rho C_{p}\left[|\mathbf{V}|^{\prime} \overline{\left(q_{s}-q_{a}\right)}+\overline{|\mathbf{V}|}\left(q_{s}-q_{a}\right)^{\prime}\right. \\
& \left.+\overline{|\mathbf{V}|^{\prime}}\left(q_{s}-q_{a}\right)^{\prime}\right],
\end{aligned}
$$

where the prime means the difference between a given experiment and the PI control experiment, a variable with an overbar denotes the PI control experiment, $D$ indicates the divergence, $\rho$ is the air density, $C_{p}$ is the coefficient, $|\mathbf{V}|$ is the surface wind speed, and $q_{s}$ and $q_{a}$ are the specific humidity at the sea surface and at $10 \mathrm{~m}$, respectively. The first terms at the right-hand side of Eqs. (3) and (4), which are associated with the circulation change, could be regarded as dynamic contributors. The second terms reflect the change of moisture, and could be regarded as the thermodynamic effects. The third terms are nonlinear terms. The moisture advection term is a small term, and we do not decompose it here.

Let us first examine the impacts of the IS-LSC and IS forcing. To explore which process dominates the hemispheric asymmetry of summer monsoon precipitation, Fig. 5 shows the moisture budget over the $\mathrm{NH}$ and $\mathrm{SH}$ monsoon domains in the LGM, IS_LSC, and IS experiments compared to PI. The diagnosis results in Figs. 5a and $5 \mathrm{c}$ show that 1 ) the advection term is negligibly small and 2) the evaporation term has nearly the same contribution in the $\mathrm{NH}$ and $\mathrm{SH}$, therefore the large difference between the $\mathrm{SH}$ and $\mathrm{NH}$ precipitation is due to the large difference in the moisture convergence (Fig. 5e). Furthermore, the hemispheric asymmetry of moisture convergence can be mainly attributed to the dynamic process-related precipitation changes, as the thermodynamic process is hemispherically symmetric (Fig. 5f). The dynamic contributors of the moisture convergence show contrasting features between the $\mathrm{NH}$ and $\mathrm{SH}$ (Figs. 5b,d,f); it means that the 

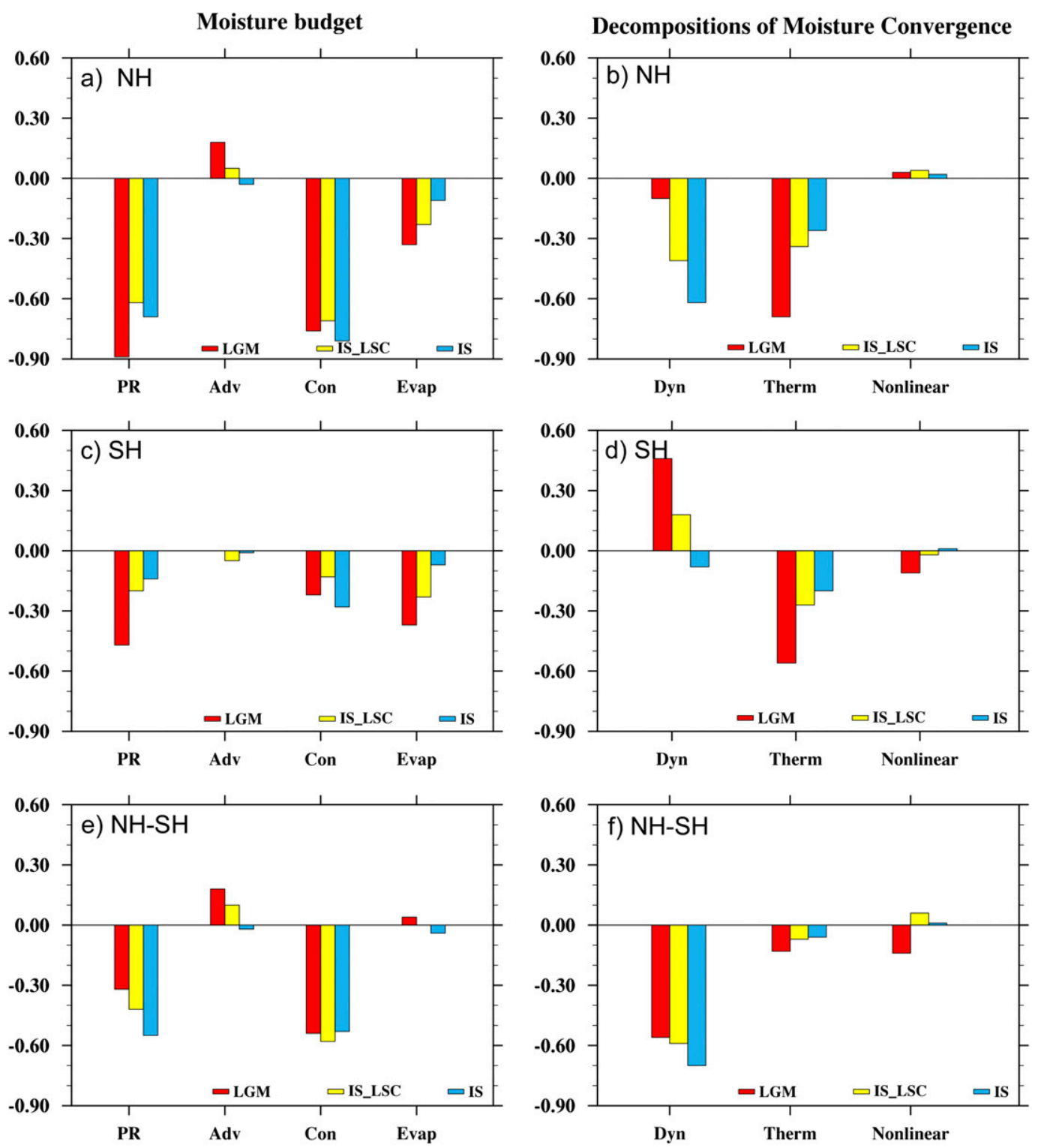

FIG. 5. Moisture process $\left(\mathrm{mm} \mathrm{day}^{-1}\right)$ responsible for the summer monsoon precipitation change $(\mathrm{PR})$ in the LGM, IS_LSC, and IS experiment. (left) The summer monsoon precipitation change is decomposed to the moisture advection term (Adv), moisture convergence term (Con), and surface evaporation term (Evap) over the (a) $\mathrm{NH}$ and (c) SH monsoon domains and (e) the hemispherically asymmetric component ( $\mathrm{NH}$ minus $\mathrm{SH}$ ). (right) Moisture convergence is further decomposed into circulation change (Dyn), moisture content change (Therm) and their nonlinear product (Nonlinear) of the two changes over the (b) $\mathrm{NH}$ and (d) $\mathrm{SH}$ monsoon domains and (f) the hemispherical asymmetric component ( $\mathrm{NH}$ minus $\mathrm{SH})$.

buildup of continental ice sheets induces more significant weakening of monsoon circulation over the $\mathrm{NH}$, leading to the hemispheric asymmetry of precipitation changes. The asymmetric monsoon circulation changes are robust when continental ice sheets exist alone or together with other forcings (Fig. 5).

Since the NHSM precipitation changes are quite different under different forcings, we further focus on the
NHSM and particularly compare the different impacts from GHG, IS, and LSC. Figure 6 shows the moisture budget for the NHSM precipitation changes in the GHG, IS, and LSC experiments. Again, the moisture convergence terms are the main reasons responsible for different monsoon rainfall changes among the three forcings, while the differences among the three experiments in moisture advection term and surface evaporation term 
a) Moisture budget

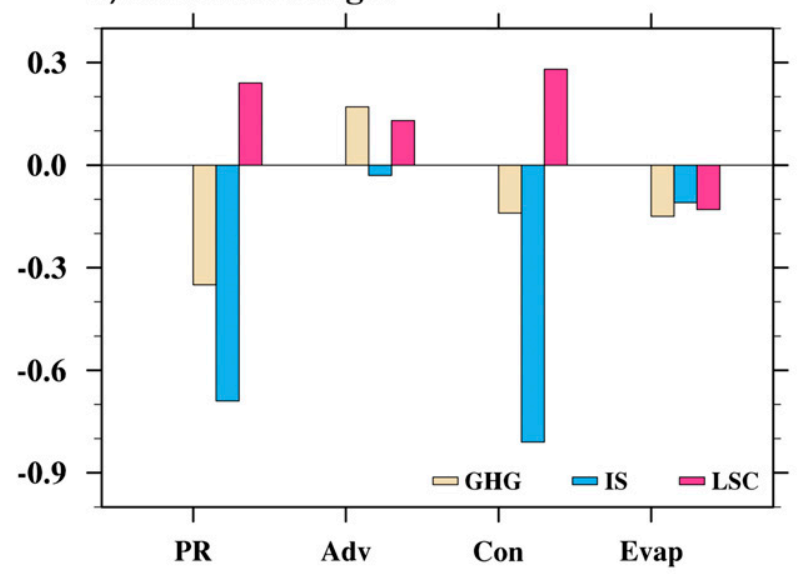

b) Decompositions of Moisture Convergence

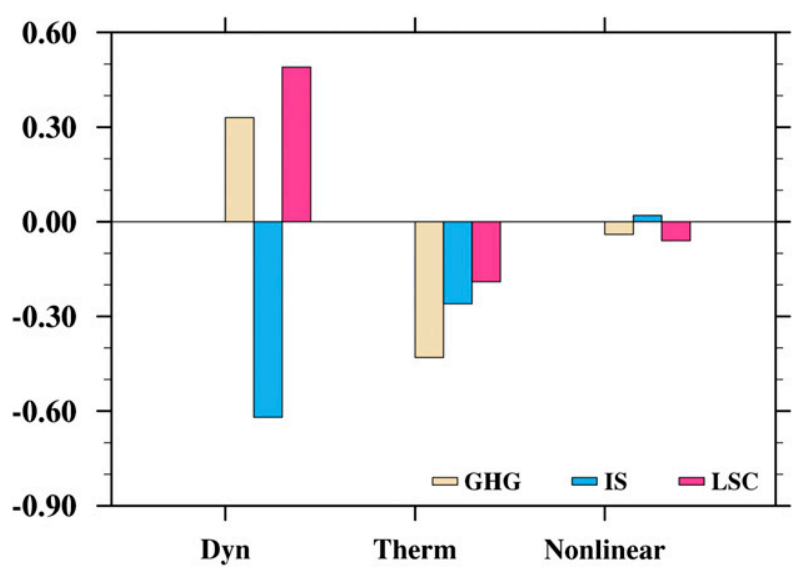

FIG. 6. Moisture process $\left(\mathrm{mm} \mathrm{day}^{-1}\right)$ responsible for the $\mathrm{NH}$ summer monsoon precipitation change (PR) in the GHG, IS, and LSC experiments. (a) The decomposition of precipitation change into the moisture advection term (Adv), moisture convergence term (Con), and surface evaporation term (Evap). (b) The decomposition of moisture convergence into monsoon circulation change (Dyn), moisture change (Therm), and the nonlinear product (Nonlinear) of the two changes.

are small (Fig. 6a). The dynamic contributors to moisture convergence are quite different from each other, while the thermodynamic contributors show consistency with temperature changes in all experiments (Fig. 6b). Previous studies suggested that the dynamic contributor would partially cancel the thermodynamic contributor under the GHG-induced global warming (Held and Soden 2006; Vecchi and Soden 2007), yielding a smaller global-mean precipitation response. This is also the case when the atmospheric GHG concentrations are low in the LGM. In the IS and LSC experiments, however, the absolute values of dynamic contributors are much larger than the thermodynamic ones (Fig. 6b). In addition, the negative dynamic contributor of IS forcing is reinforced by the thermodynamic contributor, yielding a stronger precipitation reduction over the $\mathrm{NH}$. In contrast, when the LSC forcing is imposed, moisture convergence is dominated by the positive dynamic contributor, leading to increased precipitation over the $\mathrm{NH}$ monsoon region. Therefore, the different responses of NHSM precipitation among the forcings are due to competition between the thermodynamically and dynamically oriented precipitation changes.

Over the SH monsoon domain, the thermodynamic effects due to the decrease of atmospheric moisture play a more important role in weakening moisture convergence (Fig. 5d), leading to monsoon precipitation changes dominated by the thermodynamic process. The contribution of the dynamic component of the moisture convergence to the reduction of precipitation is higher in the NH than in the SH (Figs. 5b,d). Over the SH, the dynamic effect is canceled or overwhelmed by the thermodynamic effect in the moisture convergence budget (Fig. 5d), suggesting thermodynamically oriented SHSM precipitation change.

The unique feature of AI monsoonality during the LGM could be primarily from the LSC forcing (Figs. 4a,d). Therefore, we separately diagnose the AI monsoonality in the LSC experiment. Figure 7 shows the seasonal evolution of moisture budget over the AI domain. The seasonality of monsoon precipitation anomalies is coincident with the moisture convergence term, which is enhanced during the austral spring and summer and weakened during the austral autumn and winter (Fig. 7a). It suggests that the change of monsoonality is dominated by moisture convergence, while the decrease of surface evaporation contributes to precipitation reduction all year around. As a result, monsoon precipitation is only increased during November and December (ND). The moisture convergence and evaporation are further decomposed in Figs. 7b and 7c. The seasonal variation of moisture convergence could be well explained by the circulation change, since the thermodynamic and nonlinear terms are relatively small (Fig. 7b). Wind convergence is significantly reduced in the austral autumn and winter, but enhanced in the austral summer, especially during November and December. This is the root cause of the AI monsoonality change. In the case of surface evaporation, contribution of the thermodynamic process is only about half of that of the dynamic process, indicating the critical role of surface wind speed reduction in the year-round precipitation reduction.

In summary, the hemispherically asymmetric response of LGM summer monsoon precipitation, the complex NHSM precipitation change under different forcings and the unique change of AI monsoonality can all be attributed to the differences in moisture convergence terms. 
a) Moisture budget

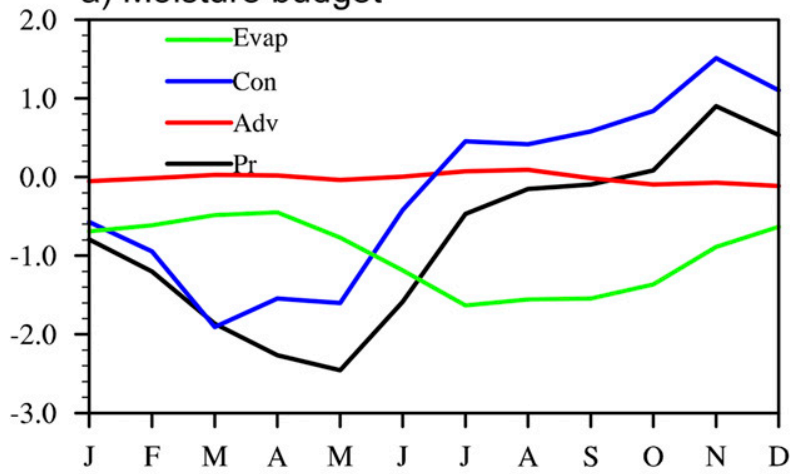

b) Decomposition of moisture convergence

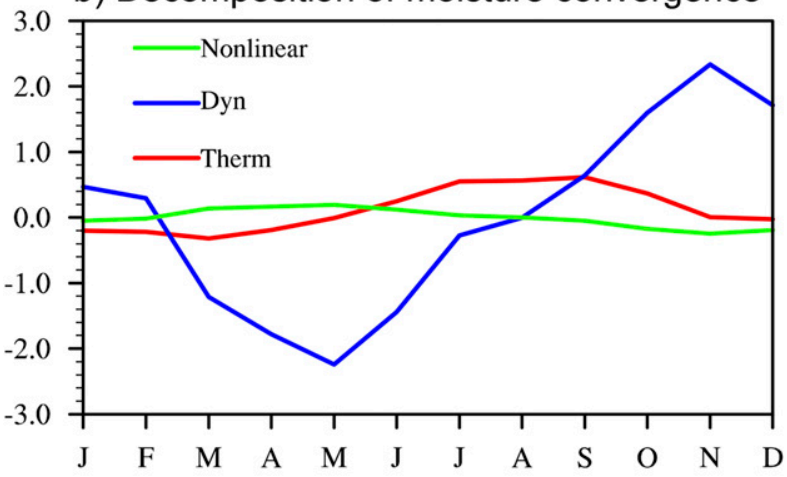

c) Decomposition of surface evaporation

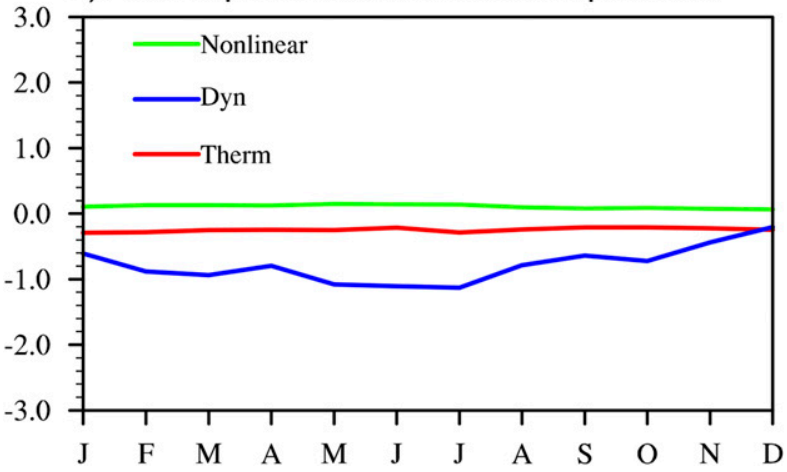

FIG. 7. Moisture processes $\left(\mathrm{mm} \mathrm{day}^{-1}\right)$ responsible for the seasonal evolution of AI monsoon precipitation in the LSC experiment. (a) The change of monsoon precipitation (Pr) due to moisture advection (Adv), moisture convergence (Con), and surface evaporation (Evap). (b) Decomposition of moisture convergence into the circulation change (Dyn), moisture change (Therm), and nonlinear product (Nonlinear) of the two changes. (c) Decomposition of surface evaporation into the circulation change (Dyn), moisture change (Therm), and nonlinear product (Nonlinear) of the two changes.

Detailed decompositions suggest that the asymmetric dynamic process due to the presence of continental ice sheets drives the hemispherically asymmetric summer monsoon precipitation changes during the LGM. In the
$\mathrm{NH}$, variation of dynamic contributors is also the reason of the difference in monsoon precipitation changes among different external forcings, while the thermodynamic contributors dominate the $\mathrm{SH}$ monsoon precipitation change. The AI region, as a unique region of the $\mathrm{SH}$ monsoon domain, experiences a wetter austral early summer (ND) and a drier condition over the rest of the year. It is influenced by the monsoon circulation change, which is controlled by the alternating land-sea configuration. The change of monsoon circulation not only modulates the moisture convergence seasonality, but also weakens surface evaporation by reducing the surface wind speed all year around.

\section{Physical mechanisms}

Why are the thermodynamic contributors comparable in the NHSM and SHSM precipitation changes? The imposed GHG, IS, and LSC forcings all cool the atmospheric temperature over the tropics, and the hemispheric difference is small (Cao et al. 2019). The vertically integrated moisture decreases in a relatively uniform sense over different hemispheres, since the atmospheric moisture content is proportional to the temperature change (figure not shown). Thus, the moisture changerelated thermodynamic contributors would be in phase over different hemispheres.

Why is the ice sheet-induced dynamic process so different in the NHSM and SHSM precipitation reduction? And why is the NHSM precipitation change more dynamics-driven? It has been suggested that the NHSM rainfall could be affected by the tropical SST gradients and the change of ITCZ (Zhou et al. 2008; Wang et al. 2013; Donohoe et al. 2013). Figure 8 compares the MJJAS-mean SST anomalies simulated in the IS and GHG experiments. When the LGM continental ice sheets are imposed, significant anomalous SST cooling is generated over the tropical North Atlantic and equatorial eastern Pacific by the enhanced North Atlantic trade wind (Chiang et al. 2003). The Atlantic meridional mode generates northerly anomalies that weaken the $\mathrm{NH}$ monsoon circulation, especially over the Atlantic sector (Fig. 9a; Chiang and Vimont 2004). On the other hand, tropical Atlantic cooling favors subtropical deep-tropospheric cooling, resulting in weakened monsoon circulation and precipitation over North America, South America, and North Africa (Kamae et al. 2017). The ITCZ location shifts southward by $0.64^{\circ}$, and the anomalous cross-equatorial energy transport is $0.2 \mathrm{PW}$ (Fig. 9b). This means that $1 \mathrm{PW}$ of across energy transport anomaly may shift the ITCZ location by about $3^{\circ}$ of latitude, which is consistent with the estimate from McGee et al. (2014). There is an 
a) IS-PI
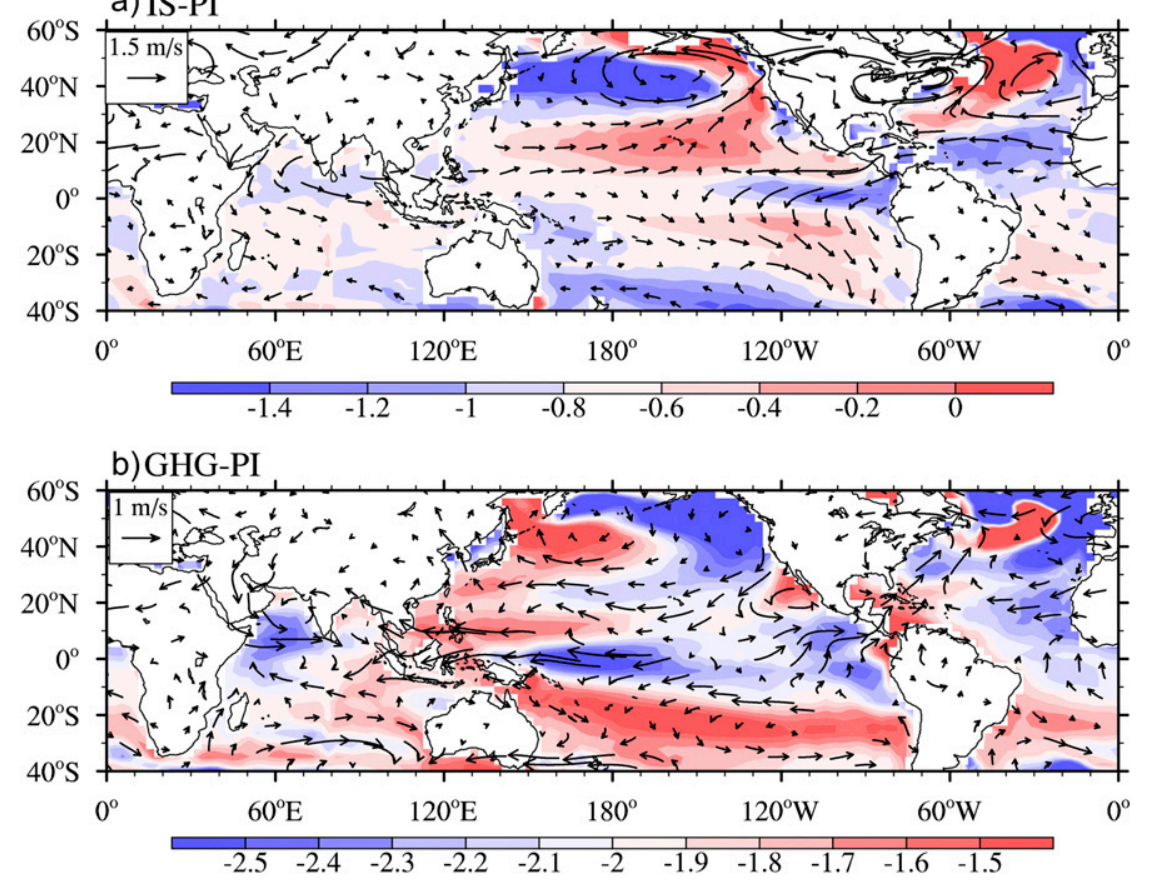

FIG. 8. The change of summertime (MJJAS)-averaged SST (shaded; K) and 850-hPa wind (vectors; $\mathrm{m} \mathrm{s}^{-1}$ ) in the (a) IS and (b) GHG experiment relative to the PI experiment.

anomalous descending motion over the latitude of the $\mathrm{NH}$ convergence zone; correspondingly, the SH Hadley circulation is enhanced. The anomalous descending motion would decrease the $\mathrm{NH}$ monsoon rainfall so that more heat could be transported to the $\mathrm{NH}$ in order to balance the NH cooling (Kang et al. 2008). Therefore, the dynamic effect of ice sheets would dominate NHSM precipitation change, leading to larger NHSM precipitation reduction. Thus the IS forcing is the major contributor to the precipitation asymmetry, and the most effective forcing in changing the NHSM precipitation.

In the GHG experiment, the SST cooling is stronger over the central (near the date line) and far eastern Pacific and western tropical Indian Ocean than over the western Pacific (Fig. 8b). The SST anomaly pattern resembles the mega-La Niña pattern proposed by Wang et al. (2013). The SST contrast between the eastern Pacific triangle and the northwestern and southwestern Pacific region would increase the SST gradient across the Pacific Ocean, and thus strengthen the Pacific subtropical highs in the Northern and Southern Hemispheres. The associated equatorial trade wind anomaly would be enhanced, leading to increased moisture convergence over the $\mathrm{NH}$ monsoon region. This is also supported by the enhanced Walker circulation and contributes to the enhanced NH Hadley circulation (Fig. 9c).
What had caused the distinct monsoonality change over the Maritime Continent during the LGM (Fig. 7)? Previous analysis suggests that the LSC forcing dominates the AI monsoon change, which is controlled by monsoon circulation changes including both wind convergence and wind speed anomalies (Fig. 7). Figure 10 compares the planetary boundary layer conditions in March-May (MAM) and ND in the LSC experiment. The choice of the two time periods is due to the distinct feature of convergence and divergence, as well as the significant surface wind speed (Fig. 7c). The change in land-sea configuration not only alters the surface albedo, but also reduces the surface moisture supply for evaporation. In the austral autumn (MAM), the land surface, especially the Sunda and Sahul Shelves, tends to be cooler than the adjacent ocean (Fig. 10a), which increases the land-sea thermal contrast and reduces atmospheric moisture content, thereby weakening convective precipitation as manifested by the BL divergence over the Sunda and Sahul Shelves (Fig. 10c). This is associated with the weakening of the Walker circulation, leading to low-level anomalous easterlies. Acceleration of the easterly induces low-level divergence over the whole AI monsoon domain. The reduced precipitation heating produces anomalous easterly over the northern Indian Ocean (Fig. 10c). However, in austral early summer (ND), solar radiation warms the 

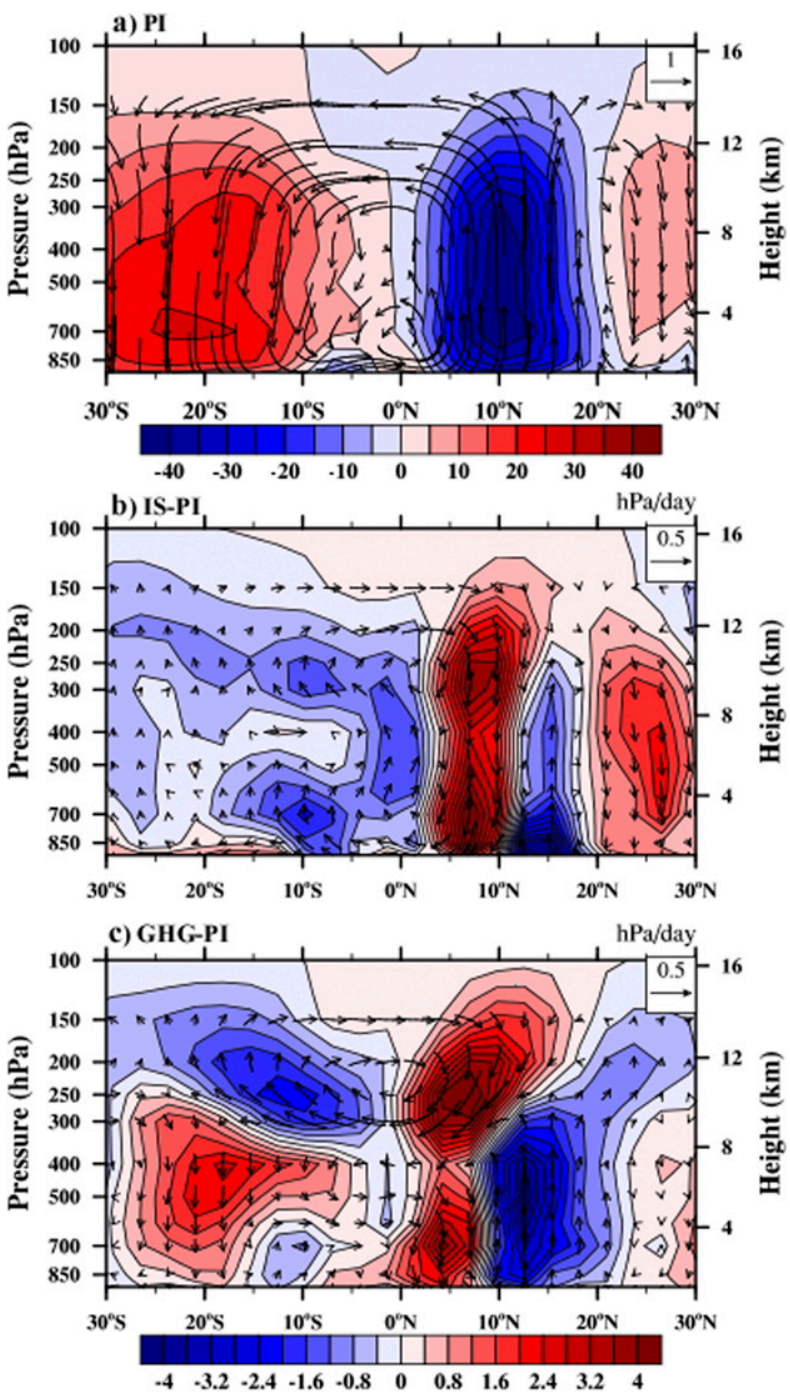

FIG. 9. (a) The zonal-mean boreal summer (MJJAS) Hadley circulation (shaded; $-\omega, \mathrm{hPaday}^{-1}$ ) in the PI experiment. The change of boreal summer Hadley circulation (shaded; $-\omega, \mathrm{hPa} \mathrm{day}^{-1}$ ) in the (b) IS and (c) GHG experiments relative to the PI experiment. The vectors are composites of the meridional wind and 100 times the vertical velocity $\left(-\omega ; \mathrm{hPa} \mathrm{day}^{-1}\right)$.

exposed continental shelf in the SH. Therefore, warm surface temperature anomalies, accompanied by low pressure anomalies, appear over the $\mathrm{SH}$ exposed landmasses, while cold surface temperature anomalies exist over the surrounding ocean and the $\mathrm{NH}$ exposed landmasses, thus enhancing the cross-equatorial flow over the Maritime Continent and generating anomalous westerlies over the eastern Indian Ocean. Consequently, the convergence is enhanced over the AI monsoon domain and thus a wetter summer monsoon is induced, although it is partially offset by decreased surface evaporation. This result is consistent with that of the
IS-LSC experiment, suggesting the robust influence of the exposure of continental shelf.

The LSC change has not only a local effect but also a remote impact through changing the equatorial eastwest circulation. The anomalous easterly over the equatorial Indian Ocean crosses the equator and turns to westerlies due to deflection induced by the Coriolis force, leading to enhanced Asian summer monsoon circulation (Fig. 11a). The enhanced ascending motioninduced condensational heating over the Indian subcontinent would in turn enhance the low-level Somali jet. Furthermore, the corresponding enhanced ascending motion over the western Indian Ocean excites the ascending Rossby response over its western side, inducing an anomalous westerly over North Africa and thus enhancing the North African monsoon circulation. Over North America, the SST gradients between the central and eastern Pacific strengthen SM precipitation. Therefore, the LSC increases the $\mathrm{NH}$ monsoon precipitation through dynamical processes against the opposing thermodynamic effect (Fig. 6).

It is clear that monsoon circulation changes are controlled by different SST patterns resulting from different forcings. The IS forcing cools North Atlantic SST, which weakens the NH ITCZ significantly and consequently leads to a dramatically weakened NHSM circulation. The La Niña-like SST pattern induced by GHG moderately enhances the NHSM circulation, while the LSC forcing strengthens the NHSM circulation by altering the Walker circulation.

As for other regional monsoons, the most appreciable change occurs over the North American monsoon region, and it is followed by the North African and Asian monsoons during the LGM period (Fig. 3a). The results of the single-forcing experiments suggested that the North American and North African monsoons are mainly influenced by the presence of continental ice sheets (Fig. 3c), while the dry Asian-Australian monsoon can be attributed to the GHG and IS forcing (Fig. 3b). As previously discussed, the cold tropical North Atlantic SST favors the southward displacement of ITCZ, especially over the Atlantic sector (figure not shown; Chiang et al. 2003). It directly weakens the North American and North African monsoon precipitation. Studies pointed out that the Asian-Australian monsoon system would be more sensitive to the GHG forcing in future projections (Christensen et al. 2013; B. Wang et al. 2014). The lower GHG forcing also demonstrates similar regional features (Fig. 4b), since it not only decreases the atmosphere moisture but also produces horizontal thermal contrasts. The "cool land-warm ocean" is more effective over the massive Eurasian continent and Pacific Ocean, which weakens the 

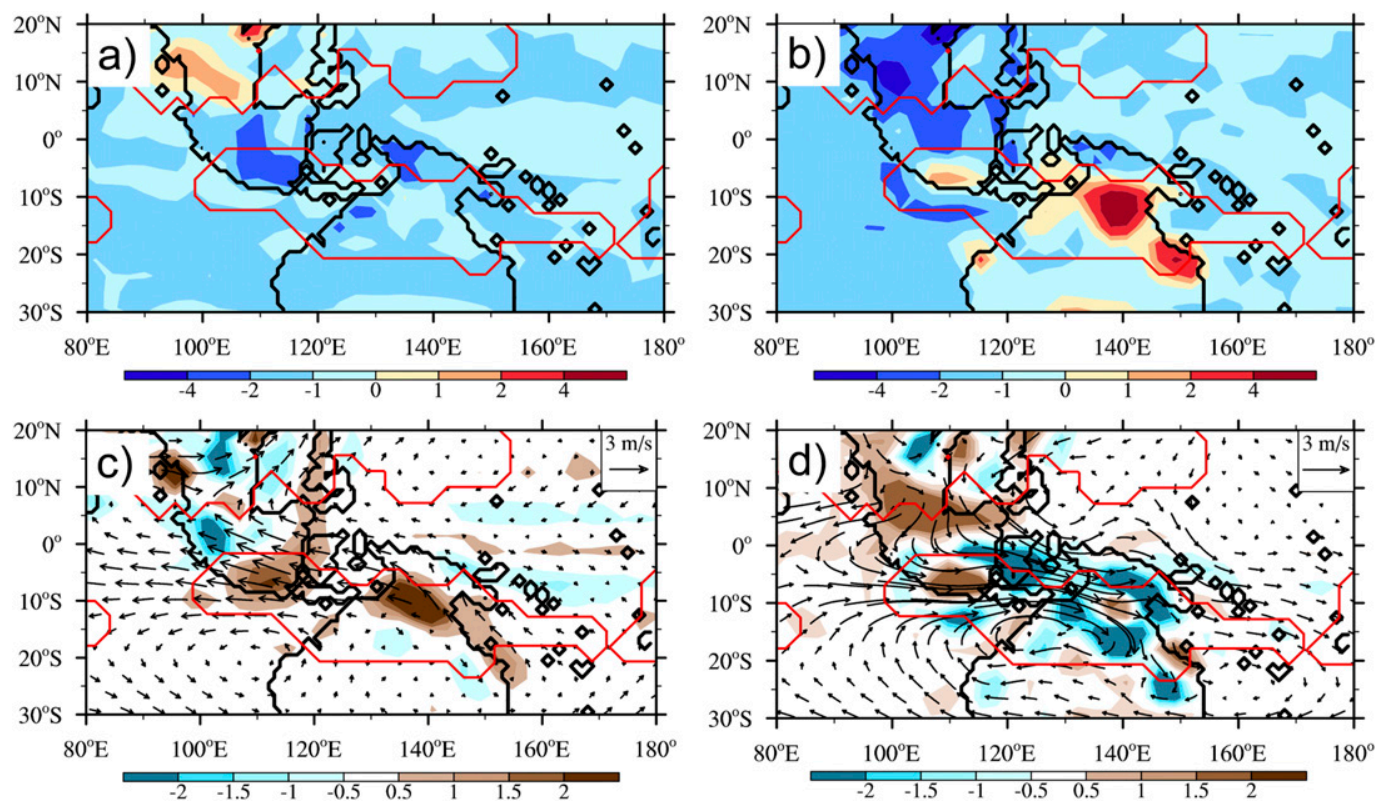

FIG. 10. The (left) MAM- and (right) ND-mean (a),(b) surface air temperature (K) and (c),(d) 850-hPa winds $\left(\mathrm{m} \mathrm{s}^{-1}\right)$ and divergence $\left(\mathrm{s}^{-1}\right)$ differences between the LSC and PI control experiments. The red lines enclose the monsoon domains. The thick black lines denote the coastal lines during the LGM.

summertime monsoon circulation. At the meantime, the "cool NH-warm SH" weakens the summertime crossequatorial flow, leading to a larger dry response over the Asian monsoon region. This is similar to the mechanism of future Asian-Australian monsoon change suggested by B. Wang et al. (2014).

\section{Summary}

Paleo-proxy data reveal that the GM precipitation is decreased and the precipitation responses are hemispherically asymmetric (Bartlein et al. 2011; DiNezio and Tierney 2013; Wang et al. 2006; Cheng et al. 2012; Mohtadi et al. 2016). Those features are difficult to explain by multiforcing framework experiments (e.g., the PMIP experiment). This study aims to investigate the roles of single forcings in the LGM monsoon precipitation changes, including the greenhouse gas (GHG), ice sheet (IS), land-sea configuration (LSC), and Earth orbital (EO) forcings, as well the combined IS-LSC forcing, and probe into the possible causes by a suite of control and forced experiments. The NESM v1 can well simulate the present-day and LGM mean states in the PI and LGM experiments, as well as the climate mean-state changes under multiexternal forcings. Results of the PI control experiment demonstrate that the model can realistically capture the global monsoon domain despite overestimation of the oceanic monsoon domain.
Compared to the PI experiment, the model simulates an $8.5 \%$ reduction of annual-mean GM precipitation and a $10.8 \%$ reduction of local summer GM precipitation during the LGM period. The LGM change is more obvious in the local summer season. The NHSM precipitation reduction is nearly twice as great as that of the SHSM, suggesting that the summer monsoon precipitation response is hemispherically asymmetric. Results of the single/combined-forcing sensitivity experiments show that the hemispheric precipitation asymmetry results primarily from the presence of continental ice sheets and is augmented by the GHG effect. This asymmetric response is also robust when the IS forcing coexists with other forcings. The column-integrated moisture budget analysis indicates that the hemispherically asymmetric monsoon precipitation change is primarily caused by the differences in moisture convergence change. Further decomposition results show that the monsoon circulation change-related dynamic process is the key. The pronounced negative dynamic effect under the IS forcing is caused by the cooler North Atlantic SST as well as the weakened NH ITCZ induced by hemispheric temperature anomalies.

Dramatic differences exist among the NHSM precipitation responses under the IS, GHG, and LSC forcings. Under the GHG forcing, the NHSM precipitation reduction is about half of that under the IS forcing, although the temperature responses are comparable in the two experiments. In contrast, the NHSM precipitation is 

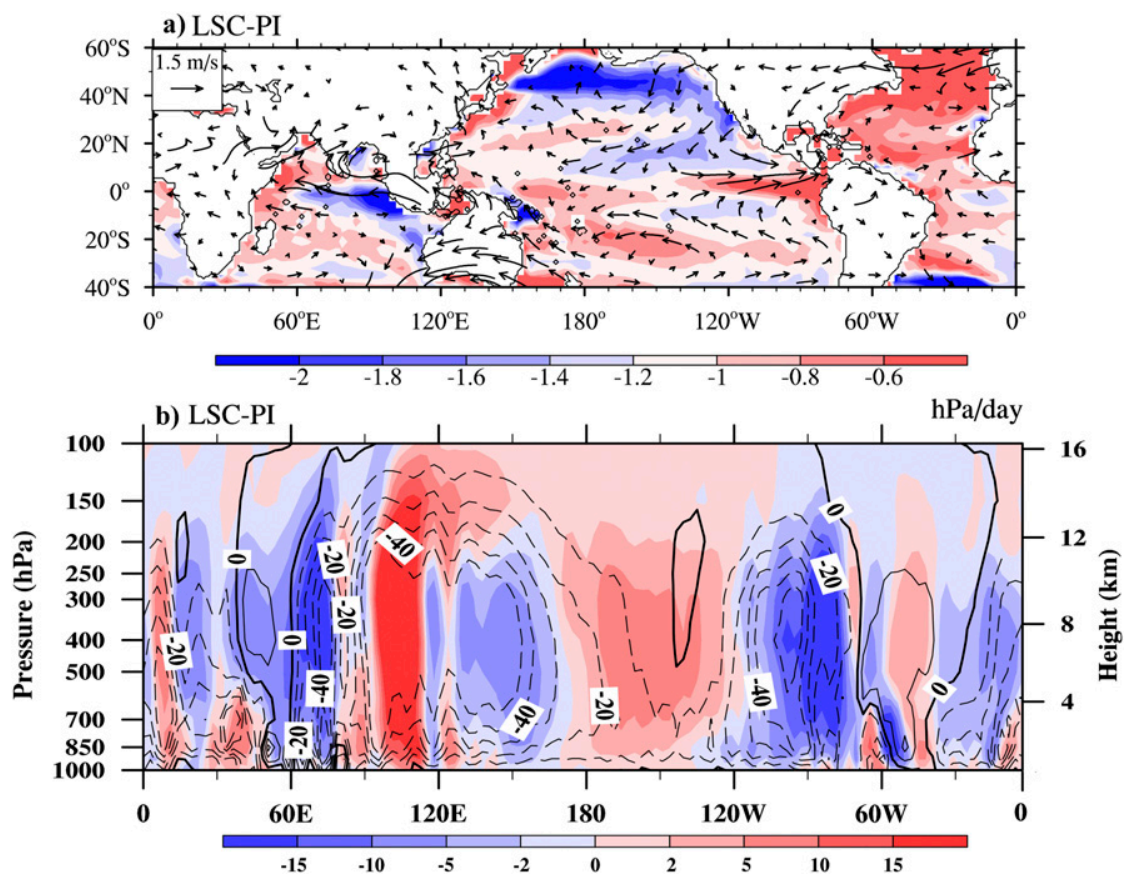

FIG. 11. The simulated change of NH summertime (MJJAS) climate in the LSC experiment relative to the PI control experiment: (a) SST (shaded; ${ }^{\circ} \mathrm{C}$ ) and $850-\mathrm{hPa}$ winds (vectors; $\mathrm{m} \mathrm{s}^{-1}$ ) and (b) Walker circulation (shaded; $\mathrm{hPa} \mathrm{day}^{-1}$ ). The black contours in (b) outline the Walker circulation in the PI control experiment.

increased under the LSC forcing. The different responses of NHSM precipitation under different forcings could also be attributed to the monsoon circulationrelated dynamic effects. The negative dynamic effect under the IS forcing is caused by both the cooler North Atlantic SST and weakened NH ITCZ, which results from hemispheric temperature anomalies. The moderate positive dynamic effect under the GHG forcing is due to the summertime mega-La Niña-like SST response. Enhancement of NHSM circulation under the LSC forcing is caused by weakening of the Walker circulation, which directly strengthens the Asian monsoon circulation. Change of the Walker circulation induces anomalous western Indian Ocean heating, and further enhances the North African monsoon circulation.

The AI monsoonality change is the main cause of LGM SH monsoonality change. The monsoon precipitation is increased during the early summer (NovemberDecember) but decreased during the rest of the year. This unique feature is caused by the LSC forcing, as the moisture convergence induced by this forcing dominates the precipitation seasonality. Comparison between the ND and MAM low-level conditions shows that the wetter austral early summer (ND) is a result of anomalous convergence due to warmer land surface and cooler adjacent ocean. This thermal contrast is more obvious in the eastern Indian Ocean. The divergent circulation during austral spring is caused by the enhanced land-ocean thermal gradients.

The understanding gained from the present study provides useful knowledge for predicting future change of the GM under anthropogenic forcing and other external forcings. However, the model results are based on a single model and the model doubleITCZ bias may affect the simulated ITCZ movement and global monsoon precipitation. Further study of the multimodel results from CMIP6 will certainly better quantify the uncertainties associated with the single model experiments.

Acknowledgments. This work is supported by the National Natural Science Foundation of China (Grants 41420104002 and 41730961), the National Key Research and Development Program of China (Grant 2016YFA0600401), the National Science Foundation (Climate Dynamics Division) Award AGS-1540783, public science and technology ocean research project funds (201505013), Natural Science Foundation of China of Jiangsu Province (BK20180812), and the Startup Foundation for Introducing Talent of NUIST (Grant 2018r063). This is Publication Number 10726 of the SOEST, Publication Number 1386 of IPRC, and Publication Number 261 of Earth System Modeling Center (ESMC). 


\section{REFERENCES}

Argus, D. F., and W. R. Peltier, 2010: Constraining models of postglacial rebound using space geodesy: A detailed assessment of model ICE-5G (VM2) and its relatives. Geophys. J. Int., 181, 697-723, https://doi.org/10.1111/J.1365-246X.2010.04562.X.

Bartlein, P. J., and Coauthors, 2011: Pollen-based continental climate reconstructions at 6 and 21 ka: A global synthesis. Climate Dyn., 37, 775-802, https://doi.org/10.1007/s00382-010-0904-1.

Bhattacharya, T., J. E. Tierney, and P. DiNezio, 2017: Glacial reduction of the North American monsoon via surface cooling and atmospheric ventilation. Geophys. Res. Lett., 44, 51135122, https://doi.org/10.1002/2017GL073632.

Braconnot, P., O. Marti, S. Joussaume, and Y. Leclainche, 2000: Ocean feedback in response to $6 \mathrm{kyr}$ before present insolation. J. Climate, 13, 1537-1553, https://doi.org/10.1175/ 1520-0442(2000)013<1537:OFIRTK $>2.0$. CO 2 .

— , and Coauthors, 2007: Results of PMIP2 coupled simulations of the Mid-Holocene and Last Glacial Maximum-Part 2: Feedbacks with emphasis on the location of the ITCZ and mid- and high latitudes heat budget. Climate Past, 3, 279-296, https://doi.org/10.5194/cp-3-279-2007.

Brady, E., B. Otto-Bliesner, J. Kay, and N. Rosenbloom, 2013: Sensitivity to glacial forcing in the CCSM4. J. Climate, 26, 1901-1925, https://doi.org/10.1175/JCLI-D-11-00416.1.

Cao, J., B. Wang, B. Xiang, J. Li, T. Wu, X. Fu, L. Wu, and J. Min, 2015: Major modes of short-term climate variability in the newly developed NUIST Earth System Model (NESM). $A d v$. Atmos. Sci., 32, 585-600, https://doi.org/10.1007/s00376-0144200-6.

— sion 3: Description and preliminary evaluation. Geosci. Model Dev., 11, 2975-2993, https://doi.org/10.5194/gmd-11-2975-2018.

_- B. Wang, and J. Liu, 2019: Attribution of the Last Glacial Maximum climate formation. Climate Dyn., 53, 1661-1679, https://doi.org/10.1007/S00382-019-04711-6.

Cheng, H., A. Sinha, X. Wang, F. W. Cruz, and R. L. Edwards, 2012: The global paleomonsoon as seen through speleothem records from Asia and the Americas. Climate Dyn., 39, 10451062, https://doi.org/10.1007/s00382-012-1363-7.

Chevalier, M., S. Brewer, and B. M. Chase, 2017: Qualitative assessment of PMIP3 rainfall simulations across the eastern African monsoon domains during the Mid-Holocene and the Last Glacial Maximum. Quat. Sci. Rev., 156, 107-120, https:// doi.org/10.1016/j.quascirev.2016.11.028.

Chiang, J. C. H., and D. Vimont, 2004: Analogous Pacific and Atlantic meridional modes of tropical atmosphere-ocean variability. $J$. Climate, 17, 4143-4158, https://doi.org/10.1175/JCLI4953.1.

— , and C. M. Bitz, 2005: Influence of high latitude ice cover on the marine Intertropical Convergence Zone. Climate Dyn., 25, 477-496, https://doi.org/10.1007/s00382-005-0040-5.

_- M. Biasutti, and D. S. Battisti, 2003: Sensitivity of the Atlantic intertropical convergence zone to Last Glacial Maximum boundary conditions. Paleoceanography, 18, 1094, https:// doi.org/10.1029/2003PA000916.

Christensen, J. H., and Coauthors, 2013: Climate phenomena and their relevance for future regional climate change. Climate Change 2013: The Physical Science Basis, T. F. Stocker et al., Eds., Cambridge University Press, 1217-1308.

Cook, K. H., and E. K. Vizy, 2006: South American climate during the Last Glacial Maximum: Delayed onset of the South American monsoon. J. Geophys. Res., 111, D02110, https:// doi.org/10.1029/2005JD005980.
De Deckker, P., N. Tapper, and W. van der Kaars, 2003: The status of the Indo-Pacific warm pool and adjacent land at the Last Glacial Maximum. Global Planet. Change, 35, 25-35, https:// doi.org/10.1016/S0921-8181(02)00089-9.

DiNezio, P. N., and J. E. Tierney, 2013: The effect of sea level on glacial Indo-Pacific climate. Nat. Geosci., 6, 485-491, https:// doi.org/10.1038/NGEO1823.

, A. Clement, G. A. Vecchi, B. Soden, A. J. Broccoli, B. L. Otto-Bliesner, and P. Braconnot, 2011: The response of the Walker circulation to Last Glacial Maximum forcing: Implications for detection in proxies. Paleoceanography, 26, PA3217, https://doi.org/10.1029/2010PA002083.

_ , and Coauthors, 2016: The climate response of the IndoPacific warm pool to glacial sea level. Paleoceanography, 31, 866-894, https://doi.org/10.1002/2015PA002890.

- J. E. Tierney, B. L. Otto-Bliesner, A. Timmermann, T. Bhattacharya, N. Rosenbloom, and E. Brady, 2018: Glacial changes in tropical climate amplified by the Indian Ocean. Sci. $A d v .$, 4, eaat9658, https://doi.org/10.1126/SCIADV.AAT9658.

Donohoe, A., J. Marshall, D. Ferreira, and D. McGee, 2013: The relationship between ITCZ location and cross-equatorial atmospheric heat transport: From the seasonal cycle to the Last Glacial Maximum. J. Climate, 26, 3597-3618, https://doi.org/ 10.1175/JCLI-D-12-00467.1.

Endo, H., and A. Kitoh, 2014: Thermodynamic and dynamic effects on regional monsoon rainfall changes in a warmer climate. Geophys. Res. Lett., 41, 1704-1710, https://doi.org/10.1002/2013GL059158.

Held, I. M., and B. J. Soden, 2006: Robust responses of the hydrological cycle to global warming. J. Climate, 19, 5686-5699, https://doi.org/10.1175/JCLI3990.1.

Hsu, P.-C., T. Li, J.-J. Luo, H. Murakami, A. Kitoh, and M. Zhao, 2012: Increase of global monsoon area and precipitation under global warming: A robust signal? Geophys. Res. Lett., 39, L06701, https://doi.org/10.1029/2012GL051037.

Huffman, G. J., R. F. Adler, and D. T. Bolvin, 2009: Improving the global precipitation record: GPCP version 2.1. Geophys. Res. Lett., 36, L17808, https://doi.org/10.1029/2009GL040000.

Hunke, E. C., and W. H. Lipscomb, 2010: CICE: The Los Alamos Sea Ice Model Documentation and Software User's Manual version 4.1. LA-CC-06-012, Los Alamos National Laboratory.

Jiang, D., and X. Lang, 2010: Last Glacial Maximum East Asian monsoon: Results of PMIP simulations. J. Climate, 23, 50305038, https://doi.org/10.1175/2010JCLI3526.1.

_ Z Z. Tian, X. Lang, M. Kageyama, and G. Ramstein, 2015: The concept of global monsoon applied to the Last Glacial Maximum: A multi-model analysis. Quat. Sci. Rev., 126, 126-139, https://doi.org/10.1016/j.quascirev.2015.08.033.

Kageyama, M., and Coauthors, 2013: Mid-Holocene and Last Glacial Maximum climate simulations with the IPSL model. Part II: Model-data comparisons. Climate Dyn., 40, 24692495, https://doi.org/10.1007/s00382-012-1499-5.

Kamae, Y., X. Li, S. Xie, and H. Ueda, 2017: Atlantic effects on recent decadal trends in global monsoon. Climate Dyn., 49, 3443-3455, https://doi.org/10.1007/s00382-017-3522-3.

Kang, S., I. Held, D. Friderson, and M. Zhao, 2008: The response of the ITCZ to extratropical thermal forcing: Idealized slab ocean experiments with a GCM. J. Climate, 21, 3521-3532, https://doi.org/10.1175/2007JCLI2146.1.

Kutzbach, J. E., 1981: Monsoon climate of the early Holocene: Climate experiment with the Earth's orbital parameters for 9000 years ago. Science, 214, 59-61, https://doi.org/10.1126/science.214.4516.59.

, and B. Otto-Bliesner, 1982: The sensitivity of the AfricanAsian monsoonal climate to orbital parameter changes for 
9000 years BP in a low-resolution general circulation model. J. Atmos. Sci., 39, 1177-1188, https://doi.org/10.1175/15200469(1982)039<1177:TSOTAA > 2.0.CO;2.

Lambeck, K., A. Purcell, J. Zhao, and N.-O. Svensson, 2010: The Scandinavian Ice Sheet: From MIS 4 to the end of the Last Glacial Maximum. Boreas, 39, 410-435, https://doi.org/10.1111/ j.1502-3885.2010.00140.x.

Lee, J.-Y., and B. Wang, 2014: Future change of global monsoon in the CMIP5. Climate Dyn., 42,101-119, https://doi.org/10.1007/ s00382-012-1564-0.

Lewis, S. C., A. N. LeGrande, M. Kelley, and G. A. Schmidt, 2010: Water vapor source impacts on oxygen isotope variability in tropical precipitation during Heinrich events. Climate Past, 6 , 325-343, https://doi.org/10.5194/cp-6-325-2010.

Liu, J., B. Wang, Q. Ding, X. Kuang, W. Soon, and E. Zorita, 2009: Centennial variations of the global monsoon precipitation in the last millennium: Results from ECHO-G model. J. Climate, 22, 2356-2371, https://doi.org/10.1175/2008JCLI2353.1.

,-- M. A. Cane, S. Y. Yim, and J. Y. Lee, 2013: Divergent global precipitation changes induced by natural versus anthropogenic forcing. Nature, 493, 656-659, https://doi.org/10.1038/nature11784.

Liu, Z. Y., S. P. Harrison, J. Kutzbach, and B. Otto-Bliesner, 2004: Global monsoons in the mid-Holocene and oceanic feedback. Climate Dyn., 22, 157-182, https://doi.org/10.1007/s00382-003-0372-y.

Madec, G., and Coauthors, 2012: NEMO ocean engine. Note du Pôle de modelisation No. 27, Institut Pierre-Simon Laplace, 386 pp., https:// www.nemo-ocean.eu/wp-content/uploads/NEMO_book.pdf.

Marzin, C., N. Kallel, M. Kageyama, J.-C. Duplessy, and P. Braconnot, 2013: Glacial fluctuations of the Indian monsoon and their relationship with North Atlantic climate: New data and modelling experiments. Climate Past, 9, 2135-2151, https://doi.org/10.5194/cp-9-2135-2013.

McGee, D., A. Donohoe, J. Marshall, and D. Ferreira, 2014: Changes in ITCZ location and cross-equatorial heat transport at the Last Glacial Maximum, Heinrich Stadial 1, and the mid-Holocene. Earth Planet. Sci. Lett., 390, 69-79, https://doi.org/10.1016/j.epsl.2013.12.043.

Mohtadi, M., D. W. Oppo, S. Steinke, J. W. Stuut, R. De Pol-Holz, D. Hebbeln, and A. Lückge, 2011: Glacial to Holocene swings of the Australian-Indonesian monsoon. Nat. Geosci., 4, 540 544, https://doi.org/10.1038/ngeo1209.

_- M. Prange, and S. Steinke, 2016: Palaeoclimatic insights into forcing and response of monsoon rainfall. Nature, 533, 191199, https://doi.org/10.1038/nature17450.

,-- E. Schefuß, and T. C. Jennerjahn, 2017: Late Holocene slowdown of the Indian Ocean Walker circulation. Nat. Commun., 8, 1-7, https://doi.org/10.1038/s41467-017-00855-3.

Roeckner, E., and Coauthors, 2003: The atmospheric general circulation model ECHAM5. Part I: Model description. Rep. 349, Max-Planck-Institut für Meteorologie, $127 \mathrm{pp}$.

Schneider von Deimling, T., A. Gonopolski, H. Held, and S. Rahmstorf, 2006: How cold was the Last Glacial Maximum? Geophys. Res. Lett., 33, L14709, https://doi.org/10.1029/2006GL026484.

Tarasov, L., and W. R. Peltier, 2004: A geophysically constrained large ensemble analysis of the deglacial history of the North American ice-sheet complex. Quat. Sci. Rev., 23, 359-388, https://doi.org/10.1016/j.quascirev.2003.08.004.

Trenberth, K. E., D. P. Stepaniak, and J. M. Caron, 2000: The global monsoon as seen through the divergent atmospheric circulation. J. Climate, 13, 3969-3993, https://doi.org/10.1175/ 1520-0442(2000)013<3969:TGMAST >2.0.CO;2.

Vecchi, G. A., and B. J. Soden, 2007: Global warming and the weakening of the tropical circulation. J. Climate, 20, 43164340, https://doi.org/10.1175/JCLI4258.1.
Wang, B., and Q. Ding, 2006: Changes in global monsoon precipitation over the past 56 years. Geophys. Res. Lett., 33, L06711, https://doi.org/10.1029/2005GL025347.

— , and - 2008: Global monsoon: Dominant mode of annual variation in the tropics. Dyn. Atmos. Oceans, 44, 165-183, https://doi.org/10.1016/j.dynatmoce.2007.05.002.

— J. Liu, H. J. Kim, P. J. Webster, and S.-Y. Yim, 2012: Recent change of the global monsoon precipitation (1979-2008). Climate Dyn., 39, 1123-1135, https://doi.org/10.1007/s00382011-1266-z.

$-,-\longrightarrow,-,-$, and B. Xiang, 2013: Northern Hemisphere summer monsoon intensified by mega-El Niño/ Southern Oscillation and Atlantic multidecadal oscillation. Proc. Natl. Acad. Sci. USA, 110, 5347-5352, https://doi.org/ 10.1073/PNAS.1219405110.

— change of Asian-Australian monsoon under RCP 4.5 anthropogenic warming scenario. Climate Dyn., 42, 83-100, https:// doi.org/10.1007/s00382-013-1769-x.

_ - and Coauthors, 2018: Toward predicting changes in land monsoon rainfall a decade in advance. J. Climate, 31, 2699_ 2714, https://doi.org/10.1175/JCLI-D-17-0521.1.

Wang, P. X., B. Wang, H. Cheng, J. Fasullo, Z. Guo, T. Kiefer, and Z. Liu, 2014: The global monsoon across time scales: Coherent variability of regional monsoons. Climate Past, 10, 2007-2052, https://doi.org/10.5194/cp-10-2007-2014.

,,,---- Z. T. Guo, T. Kiefer, and Z. Y. Liu, 2017: The global monsoon across time scales: Mechanisms and outstanding issues. Earth Sci. Rev., 174, 84-121, https://doi.org/ 10.1016/j.earscirev.2017.07.006.

Wang, X., A. S. Auler, R. L. Edwards, H. Cheng, E. Ito, and M. Solheid, 2006: Interhemispheric anti-phasing of rainfall during the last glacial period. Quat. Sci. Rev., 25, 3391-3403, https://doi.org/10.1016/j.quascirev.2006.02.009.

Weber, S. L., and E. Tuenter, 2011: The impact of varying ice sheets and greenhouse gases on the intensity and timing of boreal summer monsoons. Quat. Sci. Rev., 30, 469-479, https://doi.org/ 10.1016/j.quascirev.2010.12.009.

Xie, P. P., and P. A. Arkin, 1997: Global precipitation: A 17-year monthly analysis based on gauge observations, satellite estimates, and numerical model outputs. Bull. Amer. Meteor. Soc., 78, 2539-2558, https://doi.org/10.1175/1520-0477(1997)078<2539: GPAYMA $>2.0 . \mathrm{CO} ; 2$

Yan, M., B. Wang, and J. Liu, 2016: Global monsoon change during the Last Glacial Maximum: A multi-model study. Climate Dyn., 47, 359-374, https://doi.org/10.1007/s00382015-2841-5.

,,,--- A. Zhu, and L. Ning, 2018: Understanding the Australian monsoon change during the Last Glacial Maximum with multi-model ensemble. Climate Past, 14, 2037-2052, https://doi.org/10.5194/cp-14-2037-2018.

Yin, Q. Z., A. Berger, and M. Crucifix, 2009: Individual and combined effects of ice sheets and precession on MIS-13 climate. Climate Past, 5, 229-243, https://doi.org/10.5194/ cp-5-229-2009.

Zheng, W. P., and Y. Q. Yu, 2013: Paleoclimate simulations of the midHolocene and Last Glacial Maximum by FGOALS. Adv. Atmos. Sci., 30, 684-698, https://doi.org/10.1007/s00376-012-2177-6.

Zhou, T., R. Yu, H. Li, and B. Wang, 2008: Ocean forcing to changes in global monsoon precipitation over the recent halfcentury. J. Climate, 21, 3833-3852, https://doi.org/10.1175/ 2008JCLI2067.1. 